\title{
Imagination and cinema
}

(Applied to the movie Erq al-Balah)

\author{
أ. م .د/ سوسن محمد عزت إبراهيم عامر
}

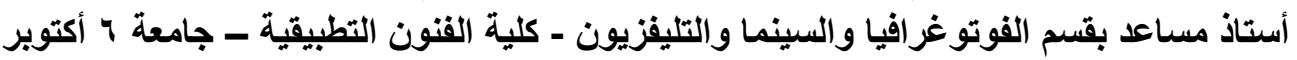

Associ. Prof. Dr. Sawsan Mohamed Ezzat

An Associate Professor at Faculty of Applied Arts -October 6 University

Photography, Cinema and Television dep., Egypt

Dr.sawsanamer@gmail.com

الملخص

يخضع الخيال للإدر الك وتؤثر كلا من الانفعالات والخبرات، و الدو افع، والتوقعات في الإدر الك. وللخيال دور كبير في اغلب الجوانب الحياتية والتفاعلات الانسانية، ويظهر بقوة في الفنون المختلفة، ولا يمكن حصره على جنس او عمر او ثقافة

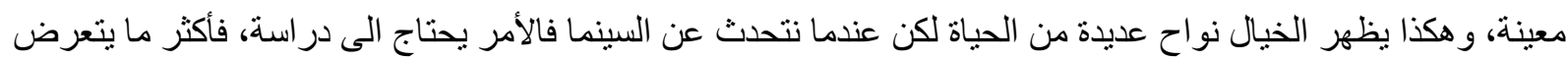
له الفيلم من هجوم يتبلور حول مفهوم و اقعية الفيلم وانه نسخ للواقع او نقل له، مما وضع الفيلم السينمائي امام مشكلة عند دراسة مدى الخيال المتاح فيه، يظهر الخيال الفيلمي على ثلاث مستويات: خيال فريق العمل، خيال المتلقي، وأخيرا قصة الفيلم ذاتها. مشكلة البحث: شكك البعض في مدى الخيال الذي يتحقق في التجربة الفيلمية السينمائية، أكثر ما تعرض له الفيلم من هجوم يتبلور حول و اقعية الفيلم و انه نسخ للو اقع او نقل له، في محاولة لنفي صفة الابداع عنه، مما يضع الفيلم السينمائي في مشكلة امام دراسة الخيال فيه، كما لا تتوفر دراسة تتناول الخيال في الصورة البصرية/السمعية بالفيلم السينمائي. أهمية البحث:

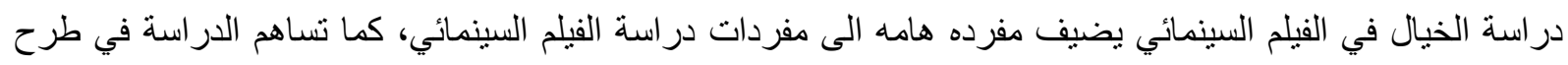
عنصر جديد الى عناصر تحليل الفيلم السينمائي ودر استة خلال بنية الفيلم. اهداف البحث: استكثاف بعض جوانب الخيال السينمائي، وكذلك دراسة الخيال كأحد عناصر الفيلم السينمائي الأساسية التي يعتمد عليها في بناءه البصري/السمعي. منهج البحث: الوصفي التحليلي، وقد توصلت الدر اسة الى مجموعة من الاستنتاجات أهمها ان الخيال الابداعي يحتل جزءا كبيرا من نسيج الفيلم السينمائي البصري/السمعي و أيضا الدر امي. وتقدم السينما هذا الخيال الخالص في شكل بصري يبدو و اقعيا. كما لا يرتبط الخيال فقط بالسينما الخيالية لكنه يظهر أيضا في كل أنواع الأفلام السينمائية من خلال عناصر الفيلم المختلفة وتطويعها المبدع خلال الفيلم.

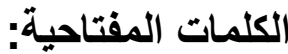
السينما، الابداع، السينما الخيالية، الصورة البصهرية، شريط الصوت

\begin{abstract}
Imagination is subject to perception and both emotions, experiences, motivations, and expectations affect perception. Imagination has a great role in most aspects of life and human interactions, and it appears strongly in different arts, and it cannot be limited to a specific gender, age or culture, and so imagination appears in many aspects of life, but when we talk about cinema, the matter needs to be studied. An attack that takes shape around the concept of
\end{abstract}


the film's realism and that it copied or transmitted the reality, which put the movie in front of a problem when studying imagination in the movie.

Research problem: Some people questioned the extent of the imagination achieved in the cinematic experience, The film was most attacked by its reality, in an attempt to deny the characteristic of creativity about it, which puts the movie in a problem when training to study imagination in it, also there is no study of fiction in film visual / audio. The importance of research: The study of fiction in cinematic film adds an important vocabulary to the vocabulary of studying film. The study also introduces a new element to the elements of film analysis and study it during the film's structure. Research Objectives: Exploring some aspects of cinematic fiction, as studying fiction as one of the main elements of cinema that depends on its visual / audio structure. Research Methodology: Analytical descriptive. Conclusions, creative imagination occupies a large part of the fabric of the film. The cinema presents this pure imagination in a visual way looks like reality. Imagination is not only related to fictional cinema, but it also appears in all types of film gender through various elements of the film and its adaptation by the creator during the movie.

\section{Keywords:}

cinema, creativity, fictional cinema, visual image, sound

\section{مقدمة:}

للخيال دور واضح في العلم عند تصور النماذج ووضع الفروض، وظهور الأفكار، وأيضا في التجارب، وكذلك الفلسفة فهو يوحي بالتصور ات والنظريات، وكذلك دراسة التاريخ ووصفه لا يمكن ان تتم دون الاعتماد على الخيال من خلال الصور المتخيلة. وكذلك التصور ات العقلية التي تنشأ لاى شعوب معينة وتظل معهم عبر الأجيال المتتالية. كذلك المنطق و التفكير المنطقي، والتفكير الناقد وحل المشكلات كلها تعتمد على طرح بدائل واختيار أفضلها، وهذا هو الجوهر الذي يقوم عليه الابداع الذي يعتمد في أساسه على الخيال، حيث ان الخيال هو البحث عن بدائل أخرى لما نواجهه فالو اقع. أوغسطين هو أول من استخدم الكلمة اللاتينية imaginatio كمقابل لكلمة تخيل phantasia، وقد استخدم كوينتيليان أيضا الكلمة اليونانية phantasia ليشير الى الصور المتخيلة بالعقل، اما مصطلح الخيال الإبداعي فقد ظهر في القرن الثامن عشر

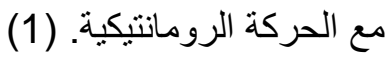
يخضع الخيال للإدر اك، و هناك فرق بين الادر الك والاحساس، فنحن نحس عندما نستخدم حو اسنا مع البيئة المحيطة لجمع

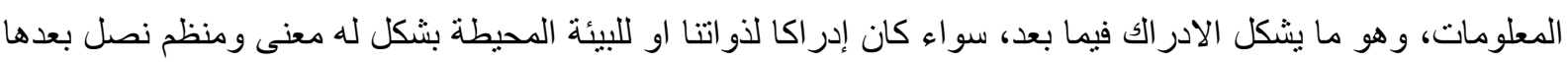
الى الوعي، ويعرف الإدر الك بأنه عملية تنظيم وتفسير البيانات الحسية التي تصل إلينا لزيادة إدر اكنا لما يحيط بنا وبأنفسنا. ويتم الخيال داخل الذهن لمحاولة إدر الك ما هو مجهول أو إيجاد حلول أو اختيار من ضمن بدائل، وبالنسبة للمخ لا يوجد فرق بين الصورة الحققية والصورة المتخيلة بالمخ، حيث تتكون الصور داخل المخ في جزء يسمي الجهاز الحوفي وقد تبين أن المخ يتعامل بنفس الطريقة مع الصورنين، أي أنه لا يفرق بين الصورة الخيالية التي يبتكرها عقل الإنسان دون أن تبصر ها عينه وبين الصورة الواقعية. ومن هنا يكون الابداع وابتكار صور بصرية هي نتاج المزج بين الواقع بصورة المدخلة الى العقل والصور المتخيلة به، و إنتاج صور مميزة جديدة. (2) إذا فالإبداع يقوم على الخيال، والقدرة على تقديم منتج او حلول مبتكرة جديدة. فأي فنان بطلق خياله لإبداع اعمال فنية مختلفة ومميزة هو مبدع واي متلقى لديه القدره على ولى 
فلك شفرات العمل الفني فهو متلقي لديه خيال. ودراسة الخيال في السينما يظهر فيها ثلاث جوانب: خيال فريق العمل في انتاج صور مبنكرة وخيال الجمهور في فلك شفرات العمل المعروض عليه والخيال الموجود بالعمل ذاته. اكثر ما تعرض له الفيلم من هجوم يتبلور حول و اقعية الفيلم و انه نسخ للو اقع او نقل له، في محاولة لنفي صفة الابداع عنها، مما يضع الفيلم السينمائي في مشكلة امام در اسة الخيال فيه، وتلاك إنكالية واجهت الفيلم السينمائي من اليوم الاول لنشأتها،

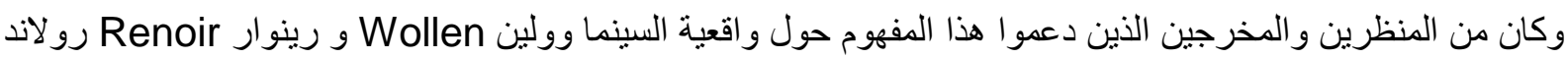
بارثيز Barthes و غير هم، الا ان هناك دراسات أخرى اثبتت ان العلامة المؤشريه و الرمزية موجودة فعليا بالفيلم ومنهم

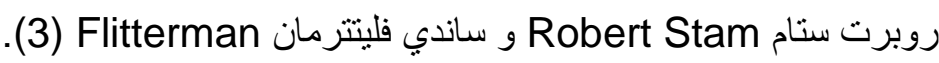
ستتناول الدر اسة الخيال خلال عناصر الفيلم المختلفة، حيث يلعب التخيل جزءا كبير ا من نسيج الفيلم السينمائي، فهو يعتمد عليه بشكل كبير ، وينقسم هذا التخيل الى:

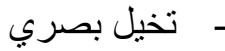
- تخيل درامي (تطور الاحداث) وهو ما يطلق عليه البناء الدرامي. اختيار فيلم عرق البلح عينة مختارة ومتعدة للتحليل حيث انه لا يندرج تحت فئة أفلام الخيال التي تشمل أفلام الخيال العلمي، و افلام المسوخ و الر عب، و الأفلام التي تتناول موضوعات تخيلية في الماضي. الا ان الفيلم قائم على فكرة ومعالجة رمزية وحدث تخيلي بالكامل، وبيداية تتابع معالج بشكل من الفانتازيا، وهو من اهم أفلام السينما المصرية و العالمية.

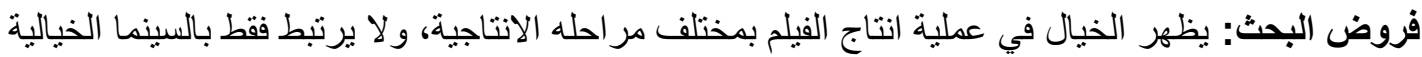

أدوات البحث و وإجراء|ته: تعتمد الباحثة على اختيار عينة عمدية من الأفلام السينمائية التي تحقق الخيال في مفرداتها. يعتمد الباحث على الملاحظة ورصد أساليب استخدام الخيال خلال الفيلم السينمائي. تصميم استمارة استبيان قائمة على عنصر الخيال فالفيلم. يتم تحكيم الاستمارة من قبل مجموعة من الأكاديميين والمتخصصين في المجال وهي عينه مقصودة نمثل نموذجا لممارسين ومتخصصين في المجال السينمائي.

\section{1 - الابداع والخيال في الفيلم السينمائي:}

المعتقدات الحقيقية والمعتقدات المتخيلة ليست سوى نوعين من الاعتقاد بالمفهوم اللغوي، ولا يمكن استبدالهما ببعضهما البعض. و التخيلات مختلفة عن المعتقدات و الر غبات الحقيقية عندما يتم حذفها من المدخلات الإدر اكية المعتادة والمخرجات السلوكية. المعتقدات و المعتقدات الخيالية نوعان مختلفان تمامًا من الأشياء. إذا تصورنا ما يلي:

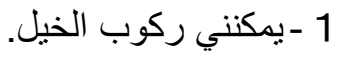
2 - الخيل الخيالي و الخيل الحقيقي هي خيل 3 - لذللك يمكنتي ركوب الخيل الخيالي. هذا التصور غير صحيح، حيث يمكن أن تخيل ركوب حصان خيالي ولكن لا يمكن حقاً ركوب مخلوق موجود فقط في الذهن(4) ، وبذلك فالسينما تعتمد على الخيال فهي لا تقدم مطلقا معتقد حقيقي بل تقدم معتقد يعتمد في جميع جو انبه على الخيال فهناك اختلاف جذري بين المتخيل والحقيقي، تستخدم السينما ما يعرف بالخيال الادراكي، الذي يظهر من اللحظة 
الاولى لعرض الفيلم والقدرة على تقبل المشاركة في احداثه، وهو اهم ما يميز الفيلم عن الادب (5) ، ويقصد بالخيال الادر اكي ان المشاهد في فيلم الفيل الأزرق لا يتخيل نفسه مثلا بجانب كريم عبد العزيز يقف امام الفيل بل يتخيل كريم عبد العزيز امام الفيل. اما فن المسرح مختلف عن فن السينما، فالعرض المسرحي مقيد بخشبة المسرح و الديكورات المتاحة فالمكان اما السينما فالخيال فيها مطلق ويمكن تحقيقه بشكل كبير ومتطرد كلما ظهر تقدم تكنولوجي جديد فتخرج صور نابضه بالحياة. كما ان الفيلم يحتاج الى فلك شفر ات بشكل اقل من المسرح، كذللك الفيلم والصورة الفوتوغر افية، فالفيلم أكثر حيوية أيضا نتيجة لان معلوماته تقدم عبر الزمن، كما انه به خبرة سمعية(6) ـ هناك أفلام تعتمد بشكل مباشر في فكرتها

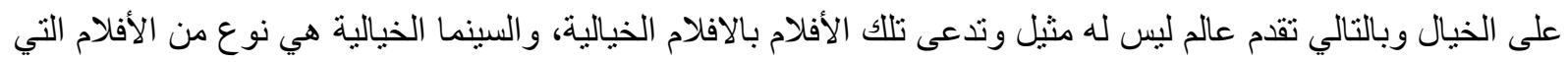
تعتمد على قصة تدور احداثها في مجال الخيال البعيدة عن نطاق الو اقع المادي الملموس، والتي قد يستحيل وجودها، فتخلق

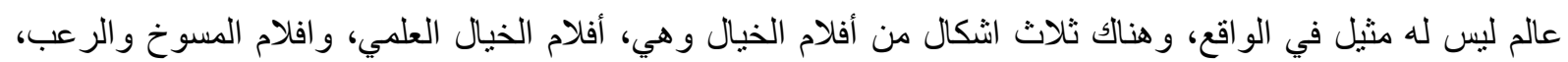

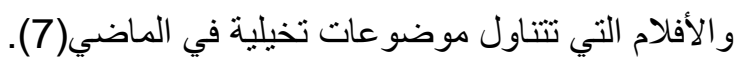
عند تناول فيلم (1993) Jurassic Park بالتحليل لا يمكن اغفال كم الابداع الناتج عن خيال فريق العمل السينمائي

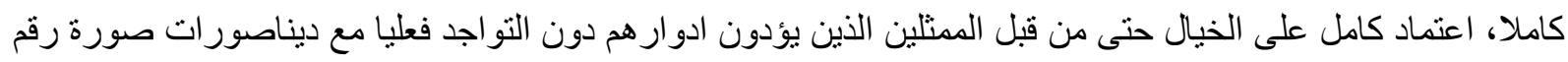

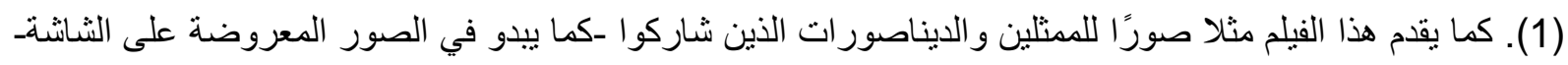
في مطاردات حقيقية بينهم وبين الديناصور ات، و هو ما ينطلب من المشاهد ان يتخيل انهم شخصيات في السرد الخيالي.

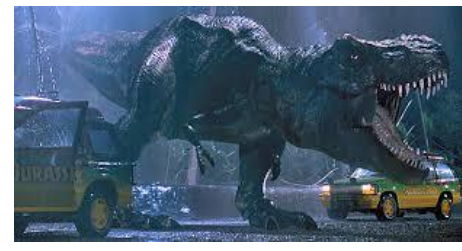

صور رقم (1)مجموعة من كادرات فيلم حديقة الايناصورات والتي يظهر فيها خيال فريق العمل لاتتاج صورة بهذا الابداع والاتقان تمثل تخيل لو اقع غير موجود

2 - التخيل في الدراسات السيميولوجيه:

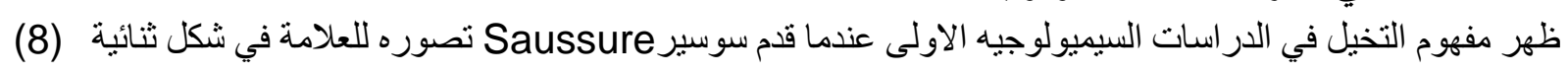
: و هما الدال signifier الذي يدل على شيء ما و هو ما يتم تحميله بالمعنى، وهو المكون الصوت او الكلمة المكتوبة،

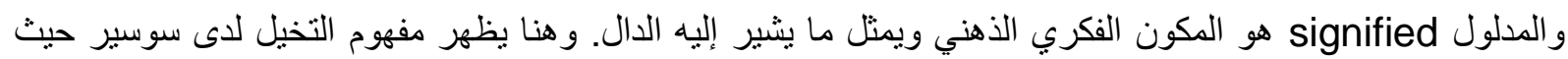
يرى ان هناك صورة ذهنية تتثكل في العقل ومرتبطة بالدال، وان العلاقة التي تربطهما سويا هي علاقة عرفية فمثلا كلمة (تفاحة) ليس هناك مبرر لارتباطها بصورة التفاحة في ذهننا سوى العرف الذي ربط بين هذه الكلمة بتلك الحروف وبين الصورة الذهنية للتفاحة بالعقل (9)، وبذلك فان العلامة هي الجمع ما بين الدال والتصور الذهني للصوت او الكلمة المكتوبة،

شكل رقم (1). 


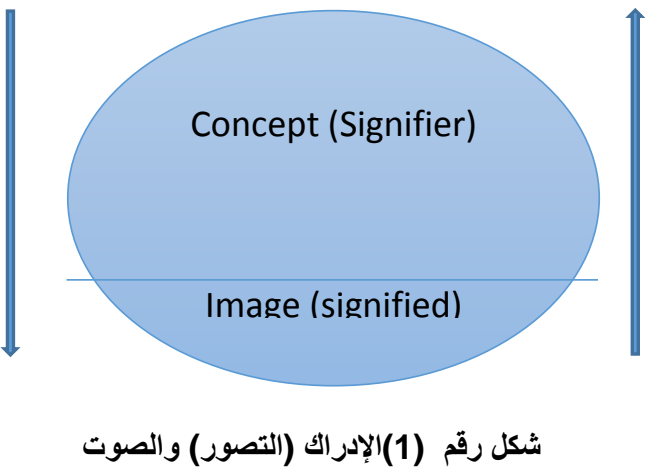

كذللك يرى بيرس Peirce ان العلامة تخلق في ذهن المتلقى علامة أخرى تكافئ العلامة الاصلية، وفي بعض الأحيان تصبح العلامة المتشكلة في الذهن اكثر تطورا، واطلق على تلك العلامة مصطلح العامل المفسر Interpretant فهو عامل يفسر العلامة الاصلية ويمثل المعنى المستمد منها (10). يتبنى بيرس مفهوم اننا جميعا نفكر بالعلامات فقط، أب اننا نتلقى علامات من البيئة المحيطة ونترجمها جميعا الى أفكار

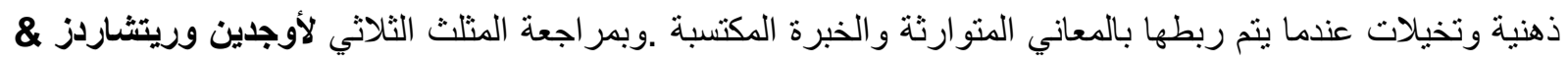
ا، يظهر الادر اك في هذا المثلث ويمثل العلامة ويتم بالذهن (11.A.Richards C.K.Ogden

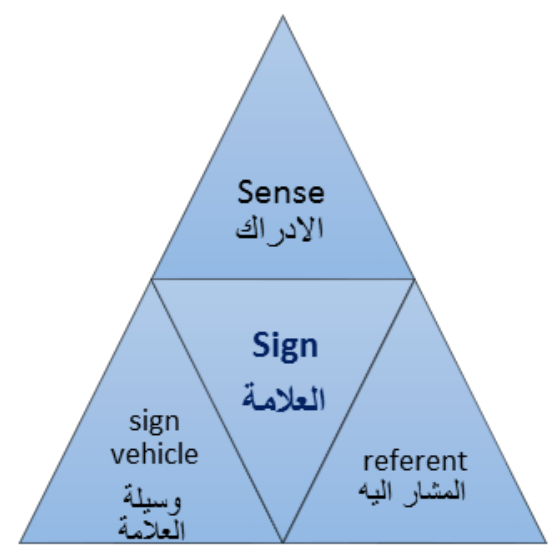

شكل رقم (2) مثلث السيميولوجي لأوجدين وريتثاردز، وليس من الضرورة ان توجد علاقة مباثرة بين المشار إليه ووسيلة العلامة

3 ـ التخيل عند رواد السينما: ميلاد السينما كان بعرض صورة الفي رواد على حائط الجراند كافيه امام جمهور 1895م، اعتمادا على حيلة الفانوس السحري، وقد ذهب البعض الى الربط بين السينما والسحر، يتحدث شاكر عبد الحميد عن ان التحويل هو جوهر السحر، و الخيال، والسينما أيضا، فما يحدث في الحالتين هو تحويل او اخر اج شيء معين الى او من شيء اخر، وبهذا الثكل فإن صناع الفيلم الخيالي هو سحرة، بالمعنى المجازي. (12) اعتمد ازنثتاين كثير ا في اعماله على مفهوم التخيل، وبتحليل اشهر تتابعين في اهم فيلم من أفلامه وهو المدرعة بوتمكن يمكن الوقوف على ذللك بوضوح تام ففي تتابع كسر الطبق من قبل البحارة وبداية العصبان يعتبر هذا مثال واضح للاعتماد

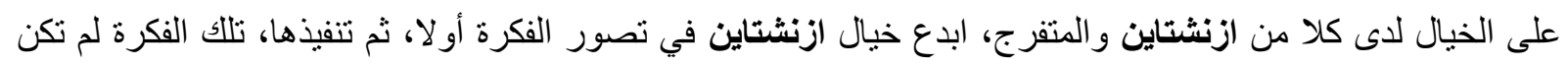
موجودة من قبل فالسينما، والتي تتلخص في الإيحاء بزمن مغاير لزمن الحدث الفعلي اذا صور بطريقة تقليدية، فقد قام

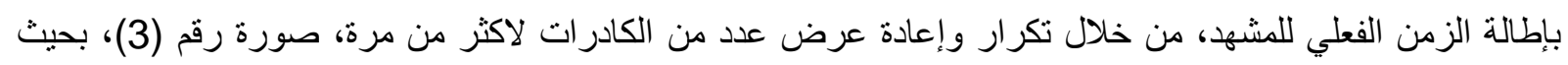

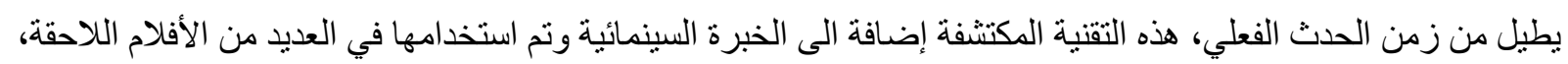


وبالفعل عند عرض الفيلم ادرك المشاهد ان هنالك إطالة فالزمن تزيد من فترة عرض الحدث عالثشاثة لزيادة التعايش معها، المقصود هو اطله الزمن كما يحدث في الواقع عندما نواجه موقفا صعبا فاننا نشعر بتباطئ الزمن، وهنا يتدخل خيال المشاهد لبعيد تشكيل الصورة الذهنية بما بنو افق مع المفهوم المرجو.
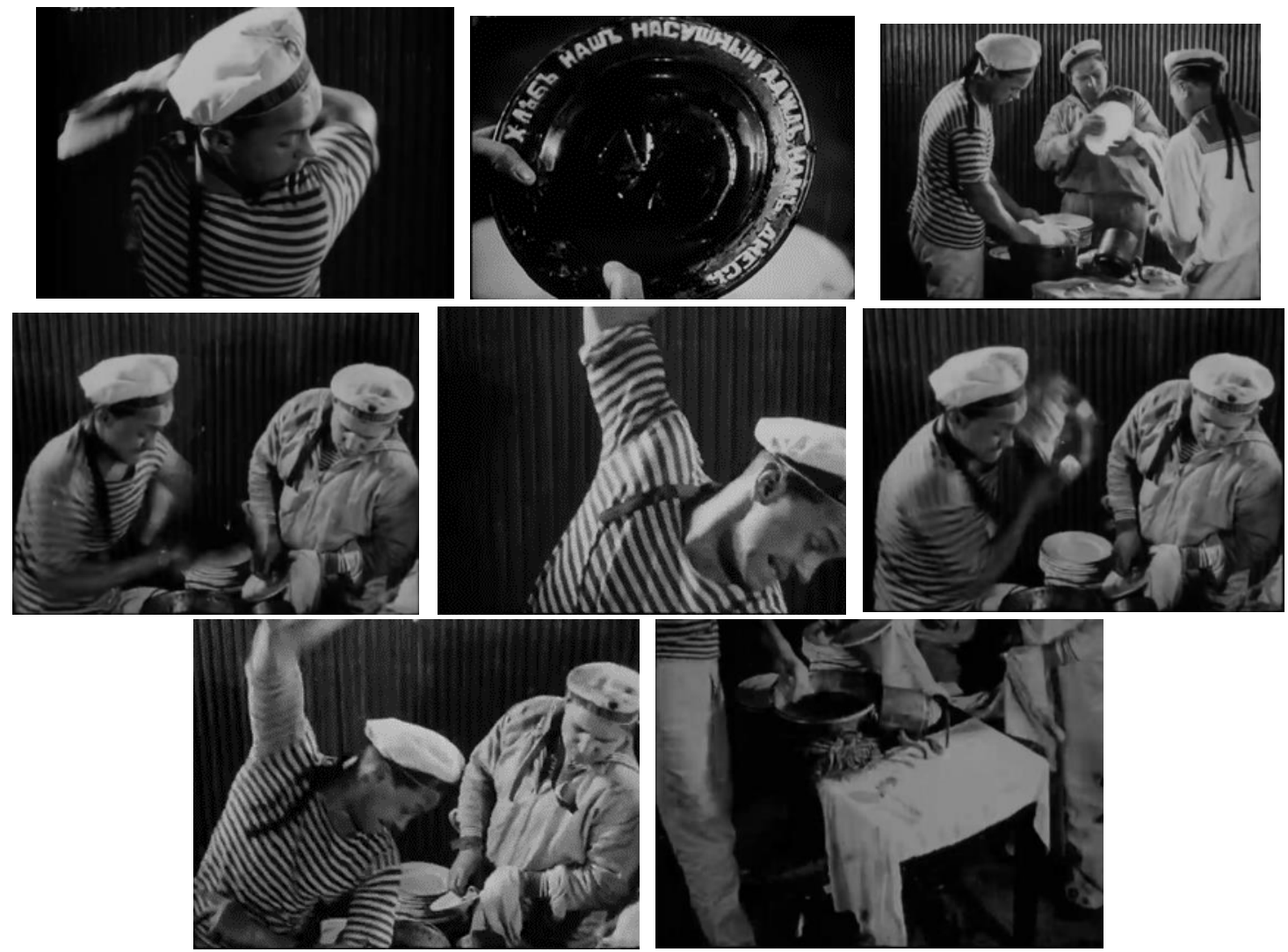

صورة رقم (3) تتابع لقطات البحارة من فيلم المدرعة بوتمكن ويظهر تكرار اللقطات لإطالة الزمن

وكذللك ما قدمه في تتابع سلالم الاوديسا بنفس الفيلم حيث أعاد عرض لقطات انزلاق عربة الطفل على سلالم الاوديسا لاكثر من مرة ليطيل الزمن فيبدو أطول من الزمن الفعلي الذي قد يستغرقة التصوير الفعلي لمثل هذا الحدث، وقد استخدم هذه التقنية لنفس السبب و هو زيادة التعايش مع التفاصيل والاحساس بالازمة وزيادة التوتر، كام قدم عرض منو ازي لانزلاق العربة مع عرض للقطات من مذبحة المدنين صورة رقم (4). ازنيشتاين اهتم كثير ا في اعماله ودر اساته بمفهوم المونتاج الفكري او الذهني، فهو يرى ان الصور المتر اصة وان كانت لا تربطها ببعضها أي علاقة حقيقية فانها توجد مفهوما ذهنيا في عقل المشاهد.

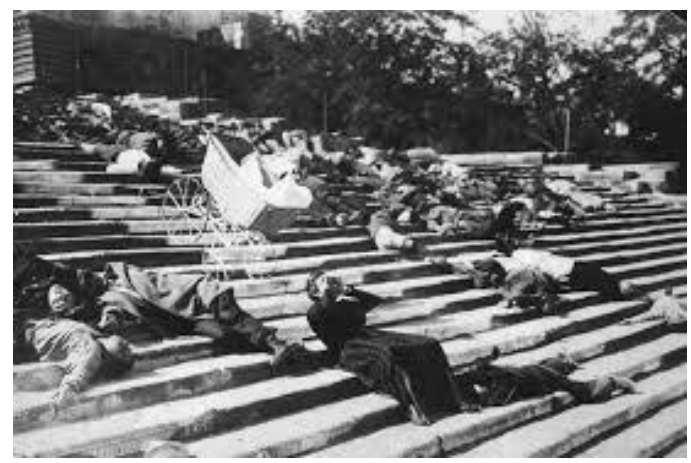

صورة رقم (4) تظهر العربة المنزلقة على سلالم الاوديسا والتي استخذت لإطالة الزمن حيث احتلت زمن المثهر كاملا الذي تناول جميع تفاصيل المقاومة لإنة 
أبدع الفريد هيتشكوك في استخدام خياله لاثارة الرعب الى اقصى درجة لدى الجمهور في فيلم Psycho ( 9 ( )، ففي تتابع مشهد القتل بالحمام وهو اشهر مشـاهد الفيلم واهم مشـاهد الرعب التي تدرس في تاريخ السينما العالمي، لم يظهر القاتل ولم يرى المشاهد جريمة القتل الفعلية ومع ذلك سبب المشهد حالة من الرعب لدى الجمهور عند مشاهدته فالسينما، فقد تخيل الجمهور جميع التفاصيل التي لم يراها و أصيب بالرعب صورة رقم (5). بناء الخوف في الفيلم اعتمد فيه هيتشكوك على جذور هذا الخوف في عقل المتفرج، وقام بتغذيته، ودعمه ليبدو حقيقا تماما عند عرضه على الثاشة، وهذا نجاح بدأ باختيار اللون الأبيض والأسود وأيضا استخدام زو ايا عين الطائر و المونتاج السريع و الحاد الذي يدعم الإحساس بالطعنات السريعة التي لم ير اها المشاهد فعليا من وجهة نظر الضحية وصرخاتها المتتالية، فقط يرى المشاهد ماريون و الدماء مع جريان الماء ولا يرى ملامح القاتل نتيجة لاستخدام اضاءة السلويت.
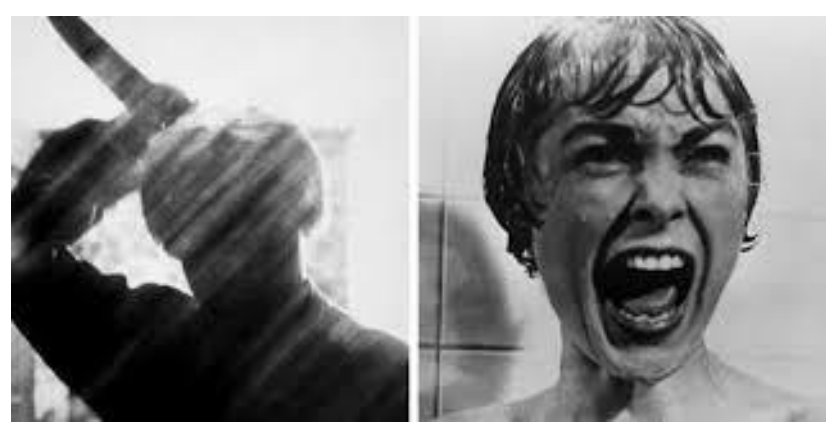

صورة رقم (5) المشهد الاكثر رعبا بفيلم Psycho والأي يظهز فيه يمينا صرخة مارين ويسارا القتال لا تظهر ملامحه بسبب الإضاءة الخلقية العلوية فئة

كذلك استخدامه للتلصص خلال الفيلم يحفز خيال المشاهد في تصور شخصية المتلصص التي تر اقب مارين، المشاهد يدرك ان المتلصص ليس القاتل بل الكامير امدا يخلق في ذهنه حالة من التونر الإضافي لانه بعي بان ذلك احد أساليب الفيلم لقول هنالك خطر يحوم عليها وحولها.

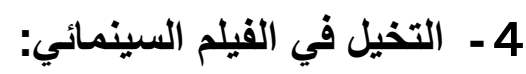

تعتمد الكثير من الأفلام السينمائية على العلامة الرمزية، والتصورات الذهنية والتخيل الذي ينشأ في عقل المشاهد، فمثلا حوار فيلم المومياء لا بذكر شيء عن إن ونيس هو حفيد هؤلاء الأجداد، ولكن الصورة البصرية تقول ذلك صورة رقم (6)، فهو يقف مماتلا لتمثال جدوده وينظر امامه بنبل وز اوية الكاميرا تؤكد وقوفهم في خط واحد سويا، في مدلول در امي تعبر عن امتداد الجذور إليه، لقطة تلخص فكرة الفيلم وتحفز خيال المشاهد نحو توقع ما ستخذه هي الثخصية من منحنى في تطور ها خلال الاحداث.

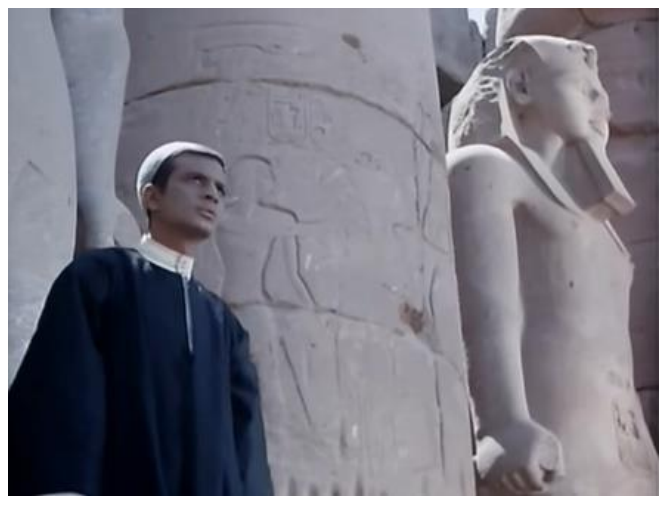

صورة رقم (6) ونيس بجانب جدوده على خط بصري واحد 
المونتاج هو عملية بنائية من تجميع الصور بجانب بعضها التها البعض لخلق فكرة في ذهن المتفرج لم تكن موجود من قبل في تللك اللقطات المنفردة. في تجربة كليشوف يظهر هذا المفهوم جليا صورة (7)، عندما صور لقطة لوجه رجل بلا أي تعبيرات

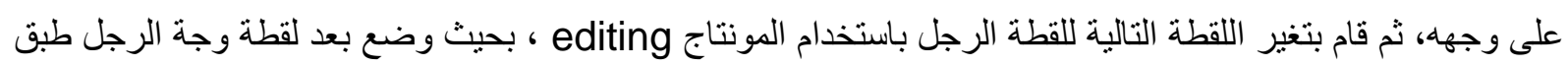

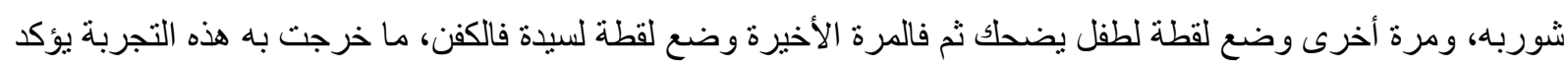

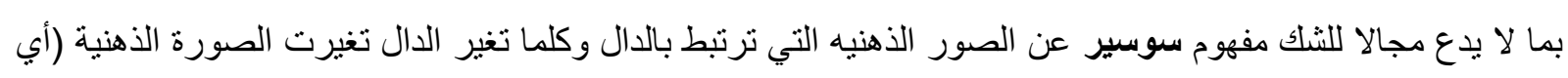

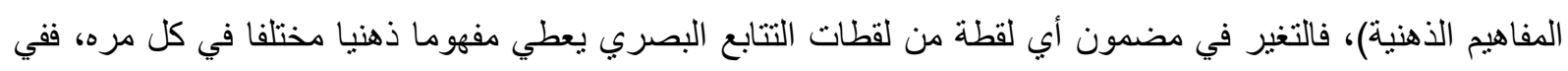
المرة الاولى فهم المشاهدون ان الرجل جائع وفي الثانية انه سعيد وفي الأخيرة انه حزين.

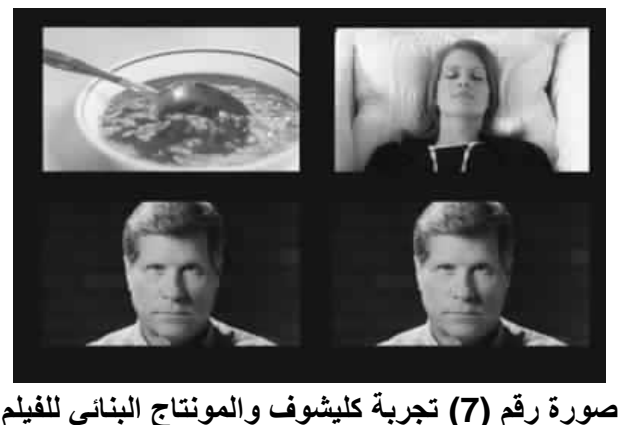

6 - التخيل السمعي فالفيلم السينمائي الموسيقى المصاحبة للفيلم على شريط الصوت تسالفي الفي أيضا في حفز الخيال و التفكير، فإيقاع وتوزيع موسيقى محدد يوحي

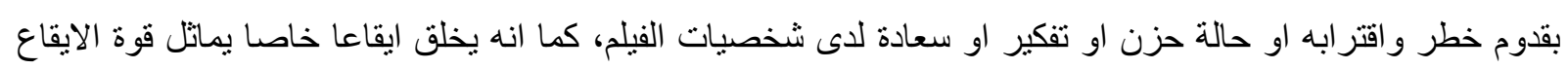

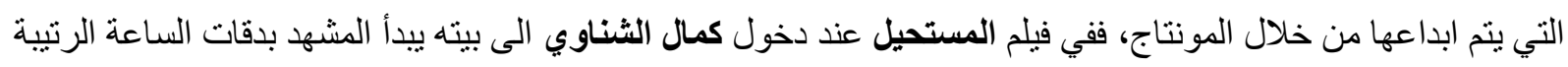

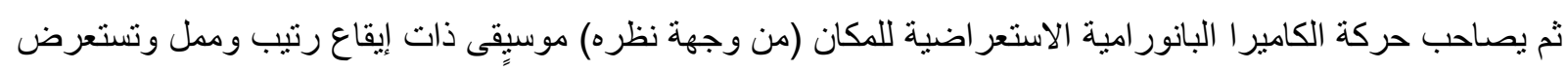
الكاميرا المكان حيث تنام زوجته كريمة مختار على احد المقاعد لكنها تبدو مع تلك الموسيقى وحركة الكامير ا قطعة اثاث كأحد قطع الأثاث التي ير اها امامه فتتساوى عنده بقيمة الأثاث القديم الكلاسيكي، في مقابل الموسيقى التي تتسم بالحيوية عند

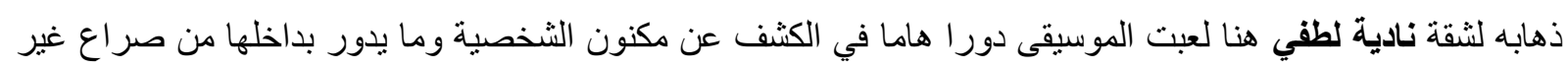
معلن بالكلمات، يترجمها ويفك شفر اتها المشاهد بعقله وخياله ليعي ويفهم الرسالة المتضمنه في المشهدين.

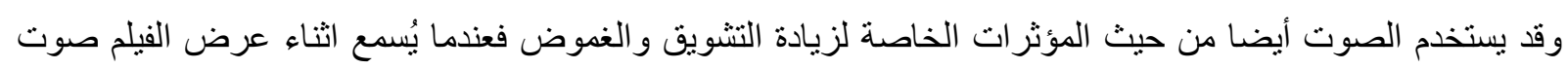

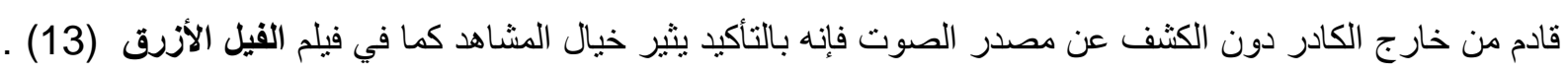
، كما ان للصمت دورا هاما أيضا فمثلا في فيلم I am a legend في مشهر ويل اسمث مع كلبه بحوض الاستحمام بالحمام، وكان ويل اسمث يقوم بتنظيف الكلب، يقف صوت الموسيقى المصاحبة القادم من خارج الكادر ثم يتوقف أيضا

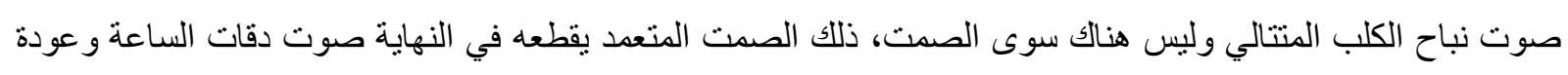

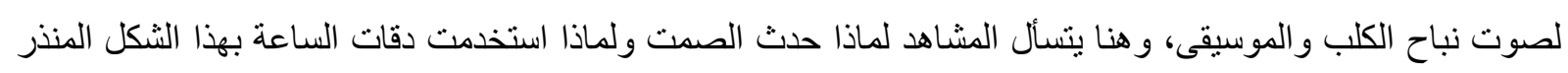
بالخطر ويدعم ذلك الإضاءة البرتقالية الدخيلة على المشهد وكذلك زاوية الكاميرا، الصمت اقوى محفز للخيال اذا استخدم 


\section{7 - التخيل البصري فالفيلم السينمائي}

الصورة السينمائية البصرية تعتمد على العديد من العناصر أهمها التكوين والاضـاءة واللون. كثير ا ما يستخدم أسلوب الإخفاء لبعض عناصر الصورة البصرية سو اء من إخفاء لثخصيات او إخفاء لموجودات مادية بموقع التصوير وذللك لإثارة فضول

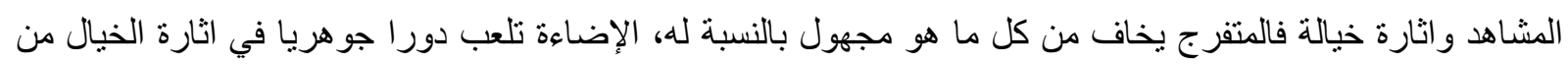
خلال شكلي الإضـاءة من الانارة والاظلام، وكما في فيلم Psycho قد نم إخفاء ملامح القاتل في مشهد قتل البطلة ماريون صورة رقم (5)، مما اثار فضول وخيال المتفرج حول حقبقة شخصية القاتل، فالر عب يأتي ويتجسد ذهنيا في ذهن المشاهد لكل ما هو موجود في منطقة الظلام بالصورة المعروضة، و على العكس أيضا قد تؤدي الانارة تؤدي نفس الدور التي يؤديه

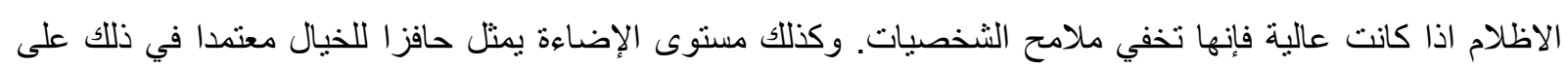

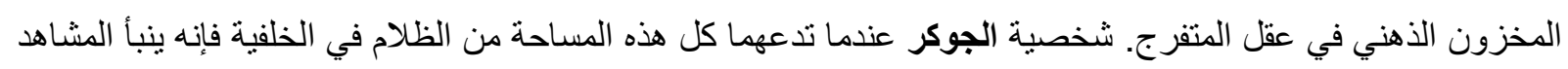
بتحو لات الثخصية الداخلية ويحفز خياله نحو ما تسنطيع هذه النخصية فعله في الجانب المظلم منها، صورة (8).

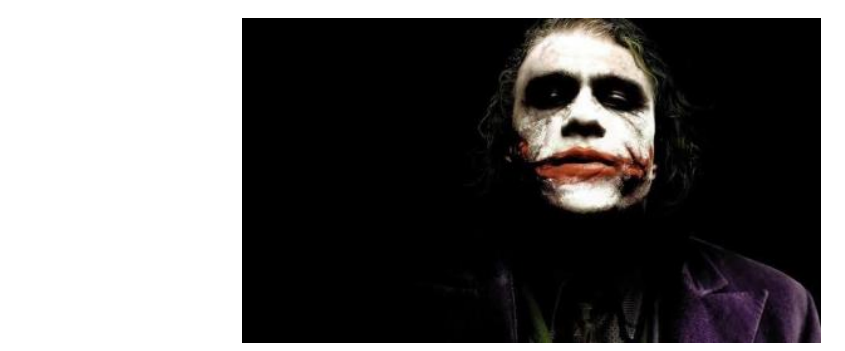

صورة رقم (8) شخصية الجوكر، استخلام الإضاءة لإثارة خيال المشاهد نحو تطور الشخصية

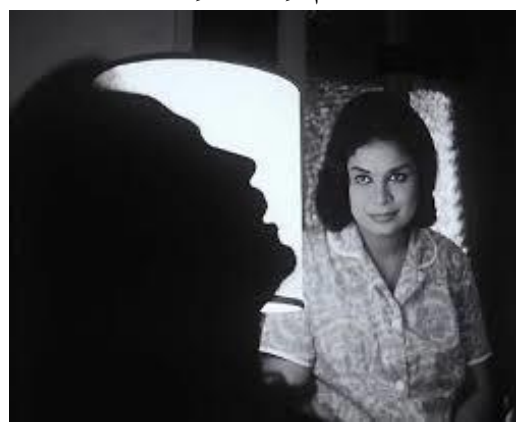

صورة رقم (9) يثير هذا الكادر صورة رقم (9) العديد من التساؤلات في ذهن المشاهد، لماذا يظهر وجهه مظلما طامسا جميع ملامحه؟، لماذا

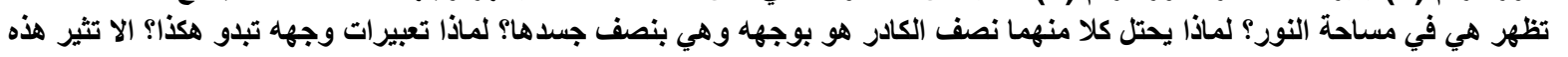

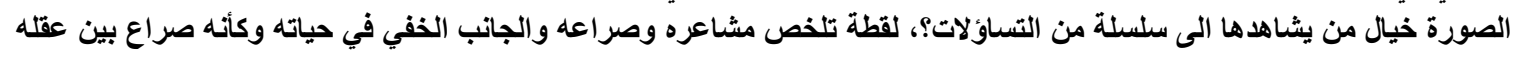
ووجودها المادي في حياته.

الأطر التي تخلقها مساحات النور والظلام تحفز لدى المشاهد مفاهيم مرتبطة بمخزونه العقلي حول هذا الثكل من توزيع

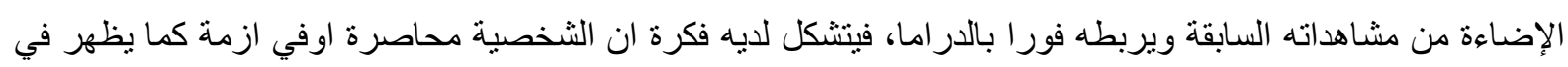

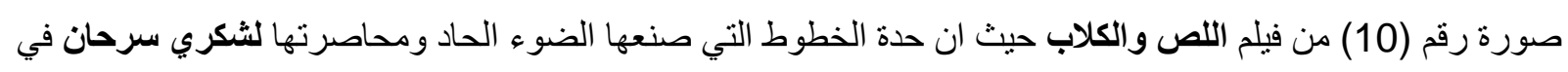
منتصف الكادر مع وجود الخطوط الر أسية الحادة، وكذللك سيطرة مساحات الاظلام على المشهد اكثر من مساحات الضوء و اصبح ظله على الأرض امتدادا له ويحتل المساحة الاكبر فلا مفر له نهائيا. 


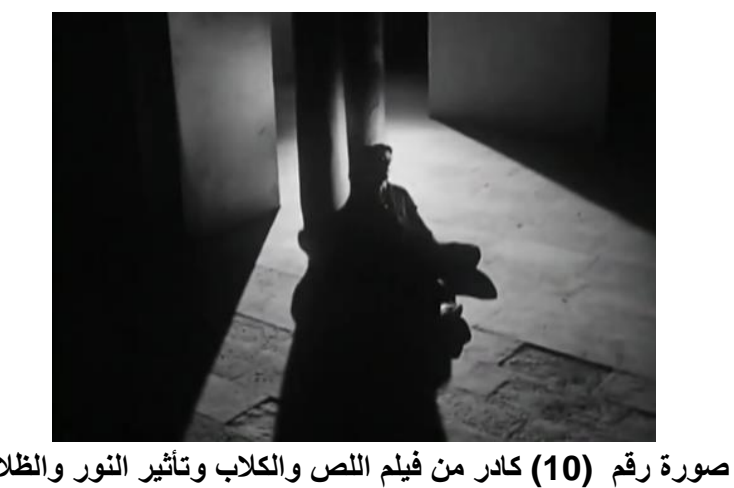

كذلك الأطر التي تصنعها مكونات المشهد لتشكل في تكوين اللقطة، فان الخطوطنوحي بمفاهيم إضافية على الحوار و الدراما، كما في شكل ه من فيلم المؤمياء فهي هنا تحفز المشاهد للتركيز وكانها تقول له (انتبه الى هذا الحوار وذللك الحدث)، صورة رقم (11). في مشهد اخر من نفس الفيلم يظهر ونيس منفردا في عمق الكادر مثرددا، تكوين يوحي توحي بالحصار و الضئالة امام التاريخ لتتناسب مع الفكرة الدرامية التي تحاصر البطل من الحيرة و المفاجأة بعدما عرف ان عائلته وسكان بلدته يقتحمون القبور ويتجارون في الاثار ويهربونها، صورة رقم (12).

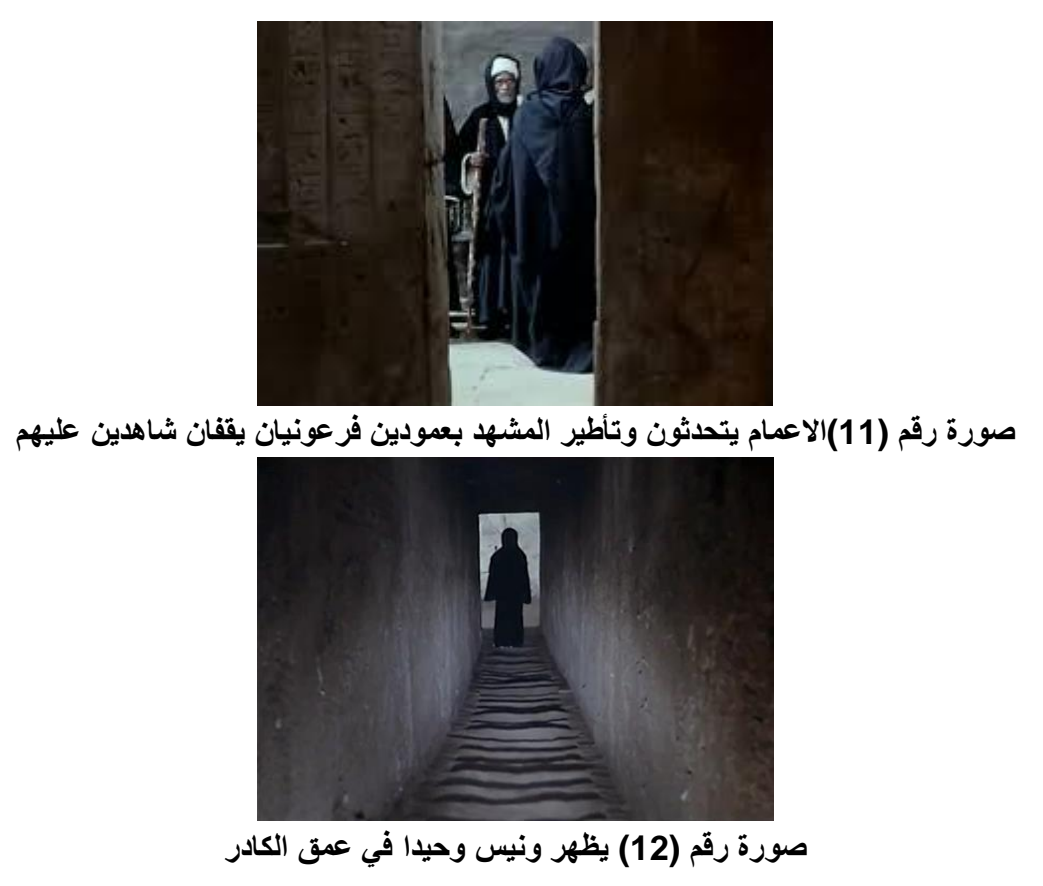

8 - تحليل فيلم عرق البلح: اخر اج وتأليف: رضوان الكاثف، و إنتاج: مدينة السينما عام 1999م، مدير التصوير: طارق التلمساني، مكساج: احمد جابر موسيقى: ياسر عبد الرحمن. يرمز فيلم عرق البلح الى التغيرات التي حلت بالمجتمع المصري بعد حرب أكتوبر، وكيف هجر الرجال الوطن وراء لقمة

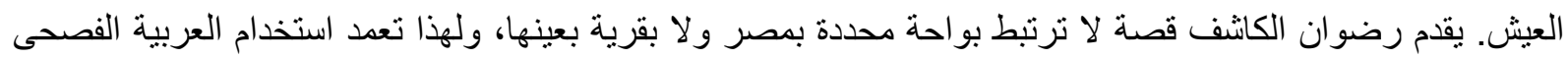

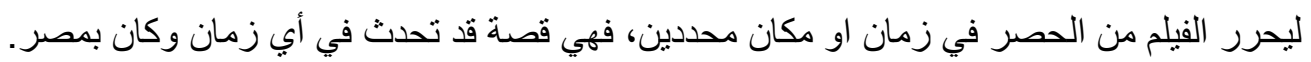


يعرض الفيلم في بدايته كيف اقتع الغريب داخل الهودج رجال القرية بالرحيل معه، لبتركو ا أهلهم وارضهم في مقابل شيء مجهول، فتركوا جميعا ماعدا احمد والجد النساء وحدهن بالواحة. دخول الهودج وبه الغريب الغامض الى الواحة، يظهر

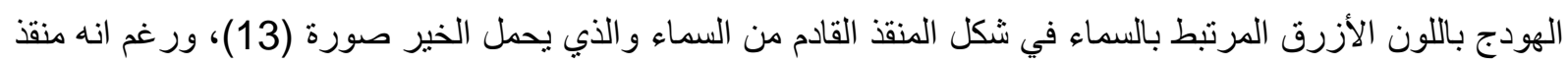

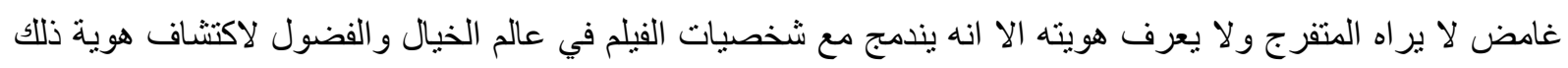

المجهول صور رقم (14)

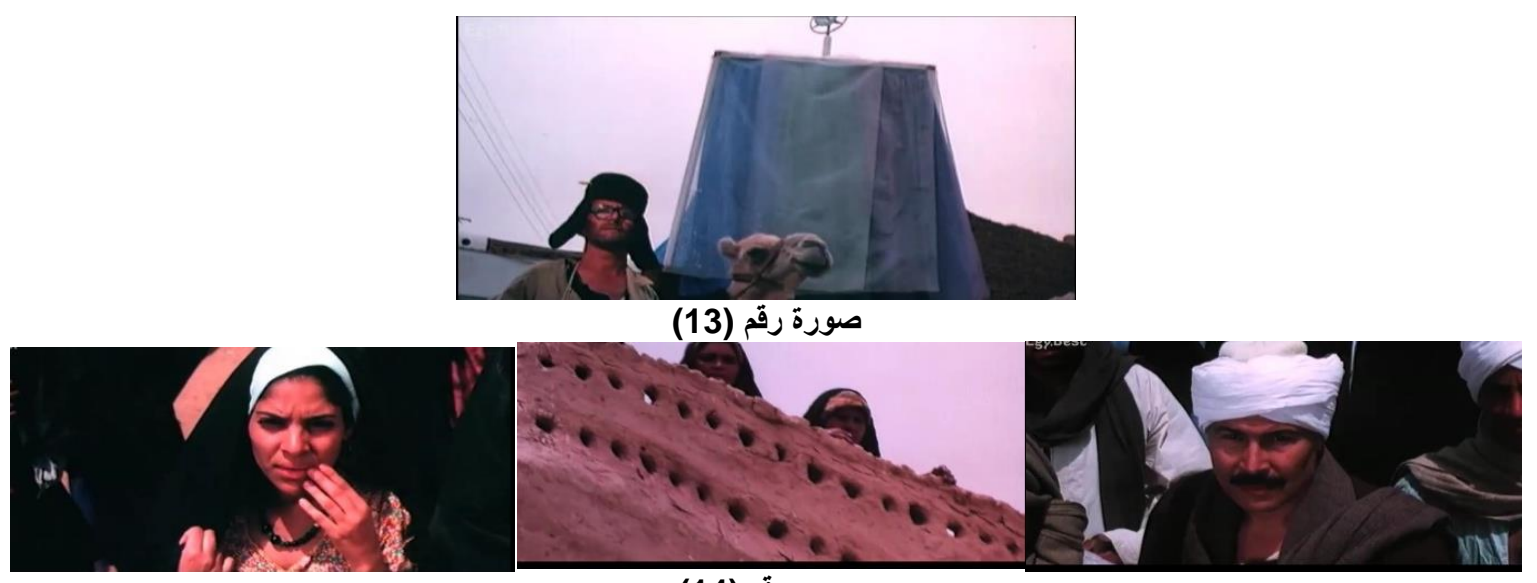

صور رقم (14)

تتحرك الكاميرا من الهودج بين أهالي القرية وكأنها الثنيطان ينحدث الى نفوسهم ويغويهم بالنقود و الذهب فيغويهم الى قبول العرض المقدم من الغريب المجهول داخل الهودج صورة رقم (15)، زيادة الاثارة المباثرة لدى المشاهد وتساؤلاته حول ما سيقدمه ذلك الغريب داخل الهودج لأهالي القرية. زوايا التصوير العلوية للهودج والسفلية للأهالي تدعم سيطرة الغريب داخل الهودج على الموقف بشكل كامل، كل تللك

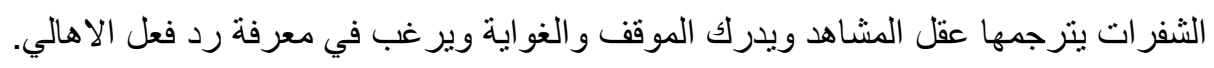

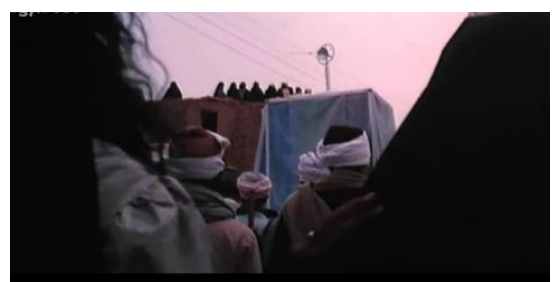

صورة رقم (15)

لم يكتفي هذا التتابع بهذا التصور الفانتازي الخيالي للغريب القادم من الخارج بل ظهر كذلك في كل من جاءو ا معه فالموظف البسيط بملابسه الغريبة كبيرة الحجم عليه، و الذي فقد هويته صورة رقم (16) هو ومن معه من مساعدين بدراجات نارية

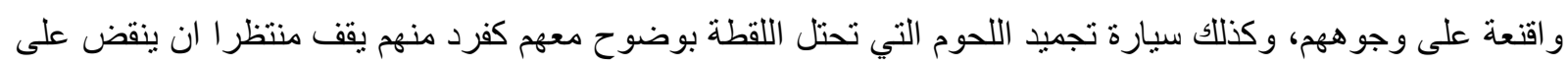
الاهالي صورة رقم (17) و (18). يدرك المشاهد حقيقة تلك السيارة ويود ان يشارك الاهالي وينبهج بعدم الدخول فيها،

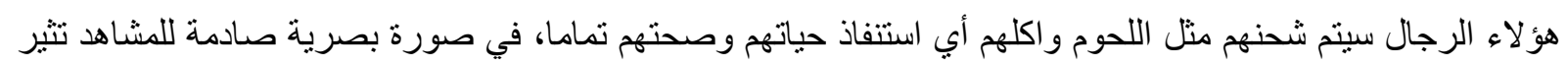
خياله بشكل كبير 

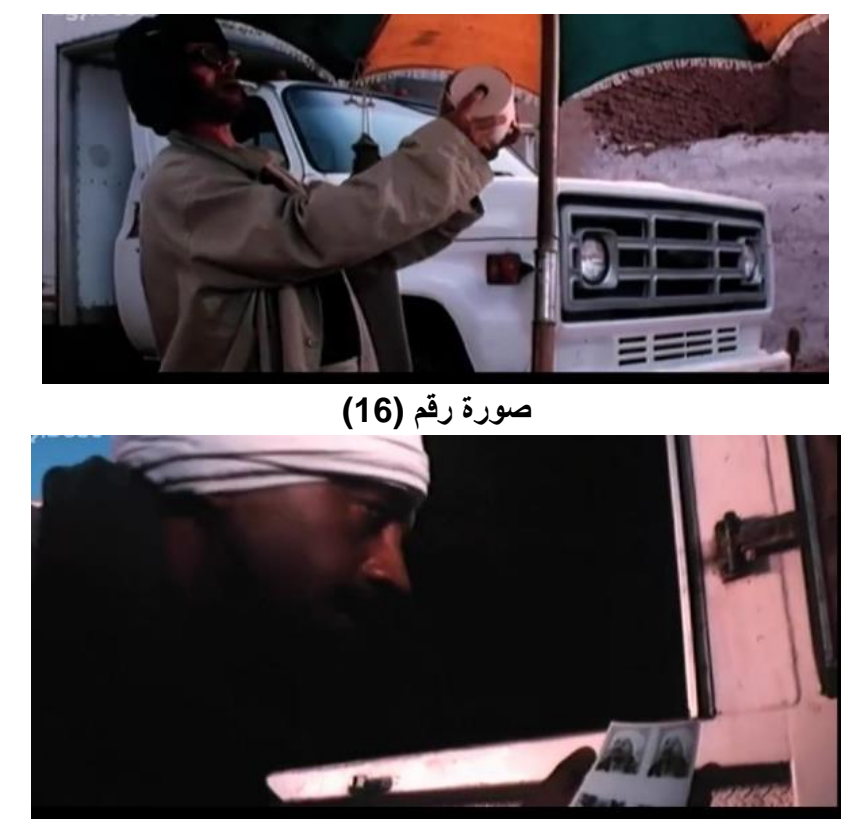

صورة رقم (17)

عندما يتحرك المقنعون الى احمد تنقلب زو ايا الكامير اليصبح احمد من زاوية علوية والمهجرون زاوية سفلية، فهو اصيل وله جذور فالأرض مثل النخلة التي يتعلق بها صورة رقم (18). احمد على لم يرحل وبقى مع الجد العجوز ، رمزا للأمل الذي يحمله الثباب ويستطيعون منحه وله كان الفتى أحمد علي هو الوحيد الذي اتخذ قراره بالبقاء في القرية مع جده العجوز، رمز أيضًا للأمل الذي يستطع الثباب

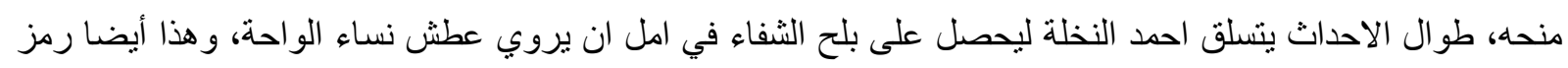
لعطشهن و اشتنياقهن لأزو اجهن، الا ان نساء الواحة العطشات لا يرنوين ابدا.

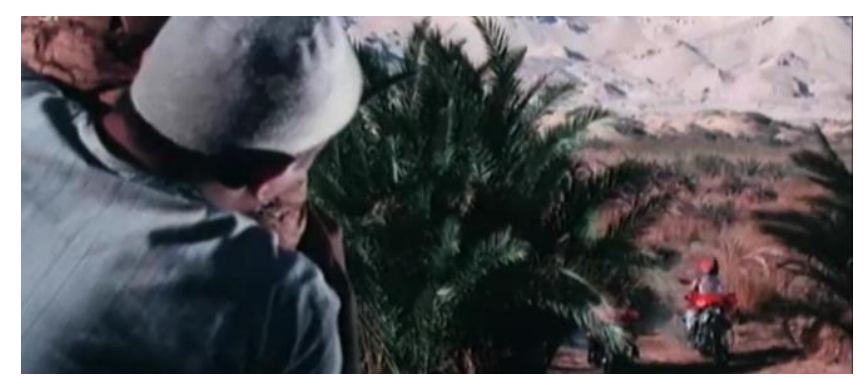

صورة رقم (18)

رمزت شريهان للحياة، وظهر ذلك في كل تفاصيل بناء الثخصية والإخر اج و التصوير ، تظهر شريهان مرتدية غطاء رأس

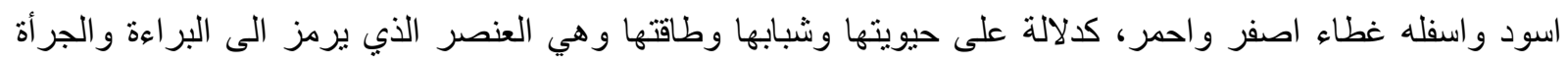
و الحيوية خلال احداث الفيلم صورة (19).

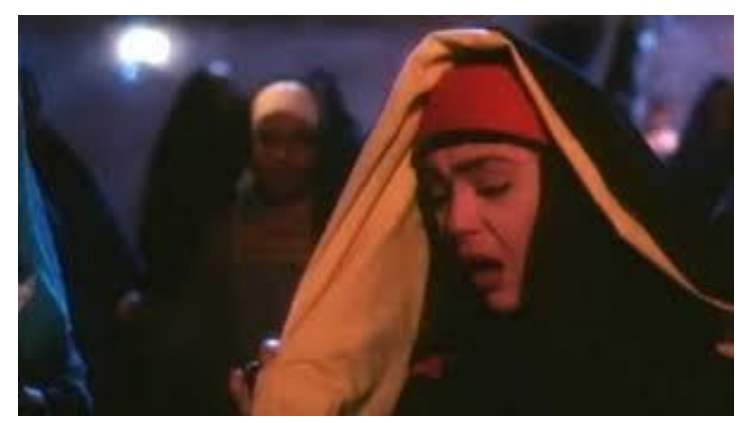

صورة رقم (19) (19) 
شريهان و التكوين المثلث المتشكل بغطاء رأسها رمز الثباتها وقتها و الاستخدام المبدع للألوان الجد خلال احداث الفيلم يمثل التاريخ، وهو يتابع في صمت وحزن طوال جميع احداث الفيلم كالتاريخ الصامت امام ما لـان

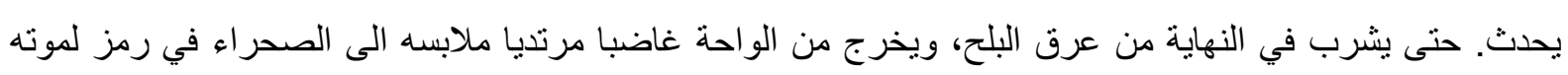

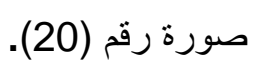

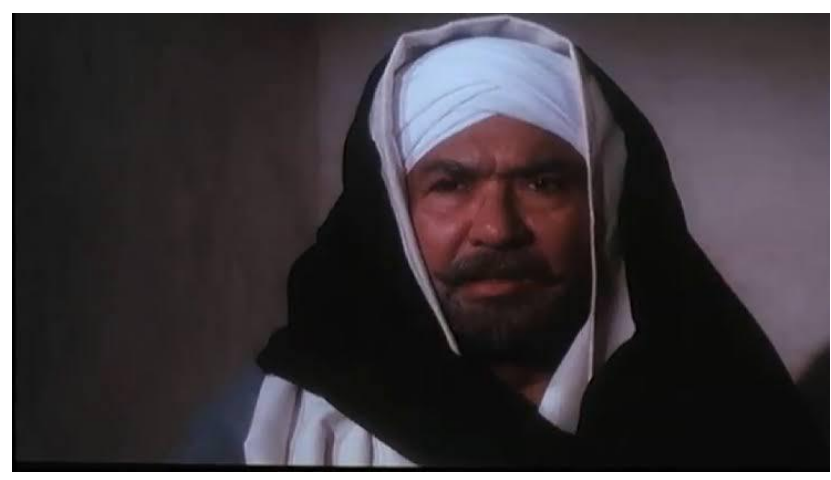

صورة رقم (20)

^- استمارة التحليل تم تحكيم استمارة الاستبيان من قبل مجموعة من الأكاديميين والمتخصصين في المجال وكان عددهم (38) وفيما يلي الاستمارة.

تم تصميم الاستمارة على برنامج Google form https://docs.google.com/forms/d/1rcZjA_6jwJVTii11YEN-

vIg8IUFXzDOgJDAb2zrDOsQ/edit\#responses

\begin{tabular}{|c|}
\hline المحور الاول : الخيال الابداعي والتصوير \\
\hline هل اثارت زوايا التصوير خيال المتلقي \\
\hline هل اثارت الإضـاءة خيال المتلقي \\
\hline هل اثارت اللونبة خيال المتلقي \\
\hline المحور الثاني: الخيال الابداعي والاخراج \\
\hline هل اثارت حركة الكامير ا خبال المتلقي \\
\hline هل اثارت التكوينات خيال المتلقي \\
\hline هل اثار استخدام اللغة العربية الفصحى في بداية الفيلم خيال المتلقي \\
\hline هل اثارت الأقنعة و الهودج خبال المتلقي \\
\hline هل بناء الثخصيات قد اثار خيال المتلقي \\
\hline المحور الثالث : الخيال الابداعي والصوت \\
\hline هل اثارت الموسيقى المصاحبه خيال المتلقي \\
\hline هل اثارت المؤثرات الصوتيه الخاصة خيال المتلقي \\
\hline هل اثار الصمت خيال المتلقي \\
\hline
\end{tabular}


مجلة العمارة والفنون والعلوم الإنسانية ــ المجلد السادس ـ العدد الثلاثون

\begin{tabular}{|c|}
\hline المحور الرابع : الخيال الابداعي في الفيلم \\
\hline هل تم فلك الثفر ات المتضمنه بالفيلم بسهولة \\
\hline هل هذا الفيلم عمل ابداعي \\
\hline هل هذا الفيلم نسخ للو اقع \\
\hline هل ارتبط الابداع في الفيلم بإثارة خيال المتلقي \\
\hline هل يظهر مفهوم الابداع الخيالي في التصوير \\
\hline هل يظهر مفهوم الابداع الخيالي في الإخر اج \\
\hline هل يظهر مفهوم الابداع الخيالي في الصوت \\
\hline
\end{tabular}

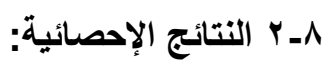
جاءت عدد استمار ات المشاركة (39) استمارة ونتائجها كالتالي:

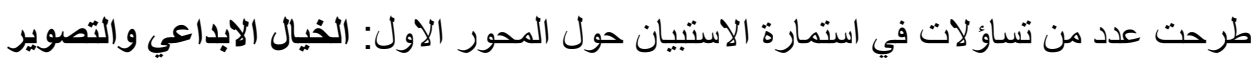
1 ـ كان السؤال الاول عن مدى اثارة زو ايا التصوير لخيال المتلقي

هل اثارت زوايا التصوير في الفيلم خيال المثلقى

39 responses

30

20

10

\section{$14(35.9 \%)$}

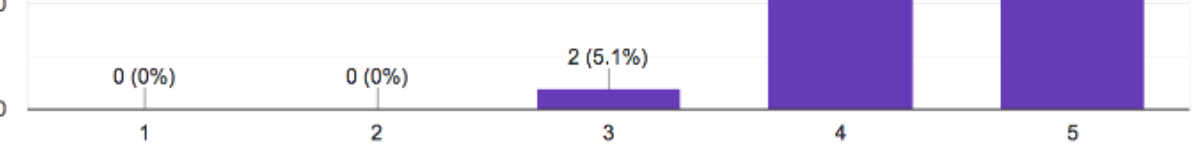

2 - كان السؤال الثاني عن مدى اثارة الإضـاءة للخيال عند المتلقي

هل اثارث الإضاءة خيال المتلقي

39 responses

30

$\sqrt{2}$

20

10

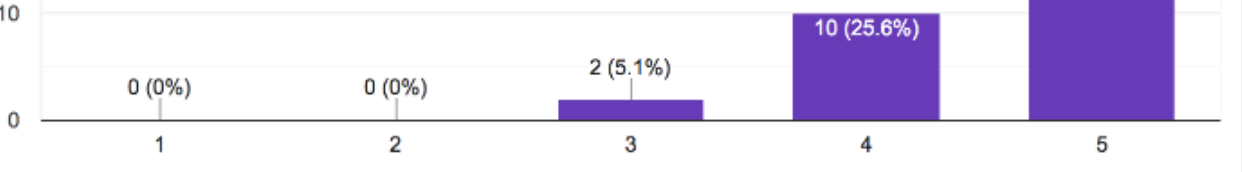


هل اثارت اللونية خيال المتلقي

39 responses

30

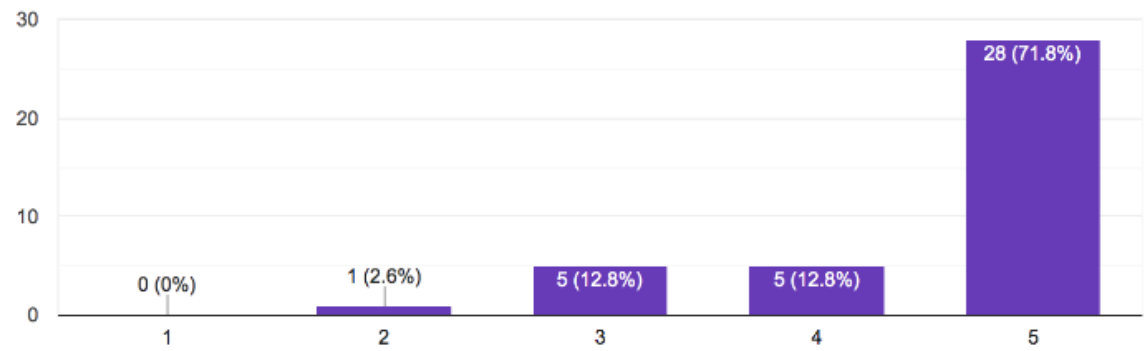

طرحت عدد من تساؤلات في استمارة الاستبيان حول المحور الثاني: الخيال الابداعي والاخراج

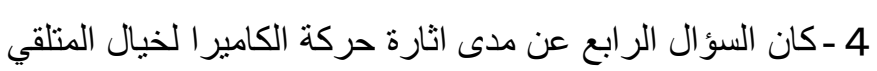

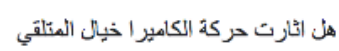

39 responses

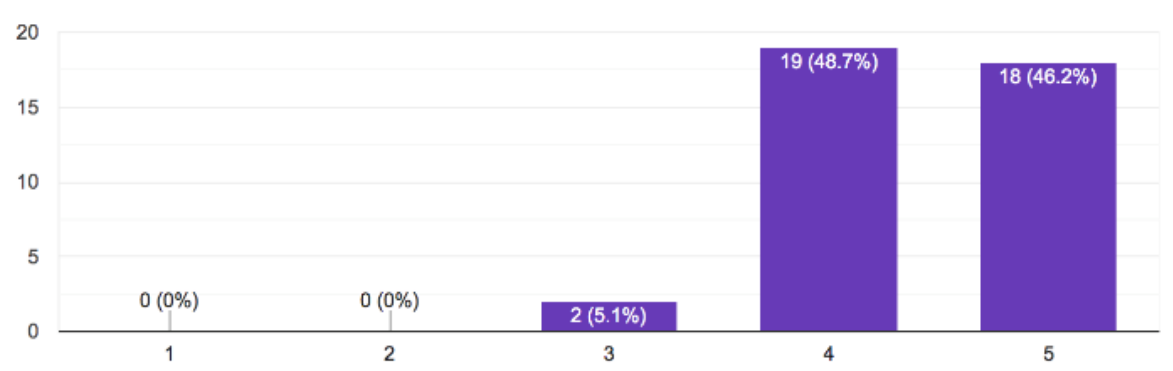

5 - كان السؤال الخامس عن مدى اثارة التكوينات لخيال المتلقي

هل اثارت النكوينات خيال المتلقي

39 responses

30

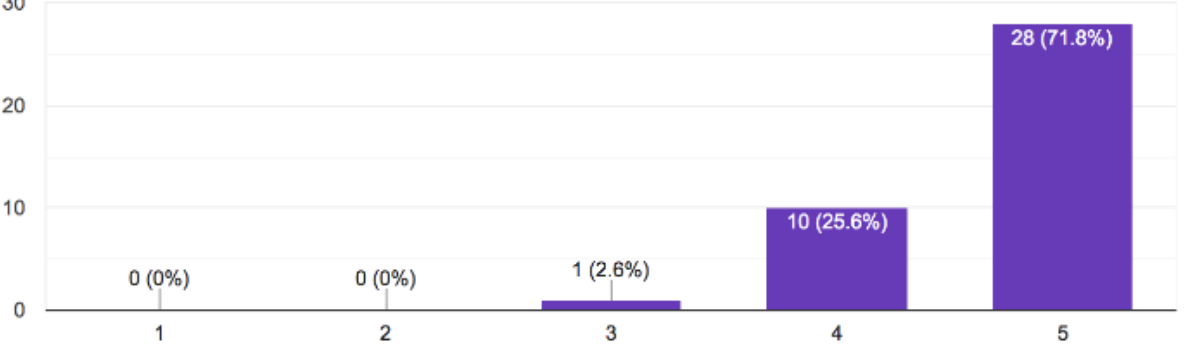


6 ـ كان السؤال السادس عن مدى اثارة استخدام اللغة العربية الفصحى في بداية الفيلم لخيال المتلقي

هل اثار استخدام اللغة العربية الفصحى في بداية الفيلم خيال المتلقي

39 responses

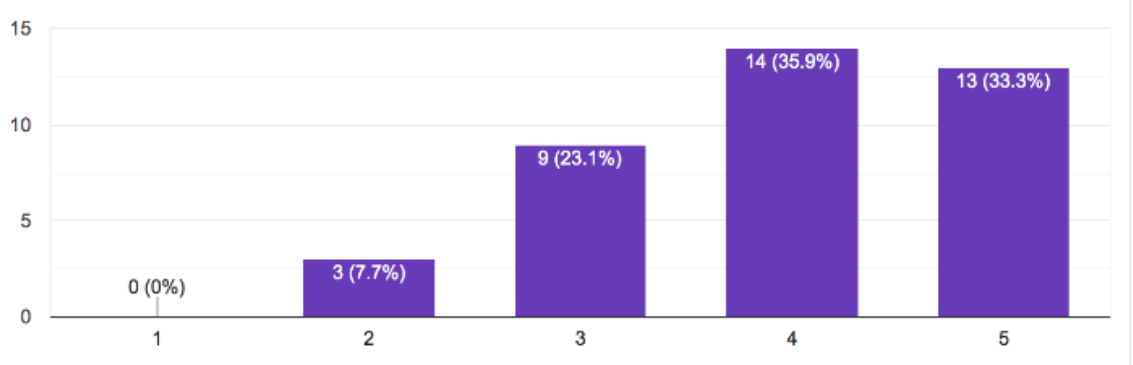

7 - كان السؤال السابع عن مدى اثارة الأقنعة و الهودج (شكل/لون) لخيال المتلقي

هل اثارت الأقتعة والهودج خيال المثلقي

39 responses

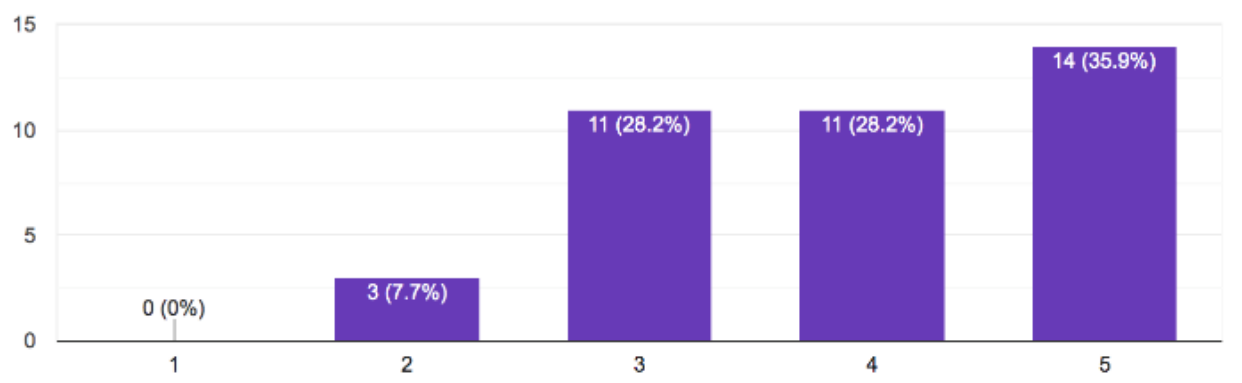

8 ـ كان السؤال الثامن عن مدى اثارة بناء الثخصيات لخيال المتلقي

هل بناء الشخصبات ثَ اثار الخيال المثلقي

39 responses

30

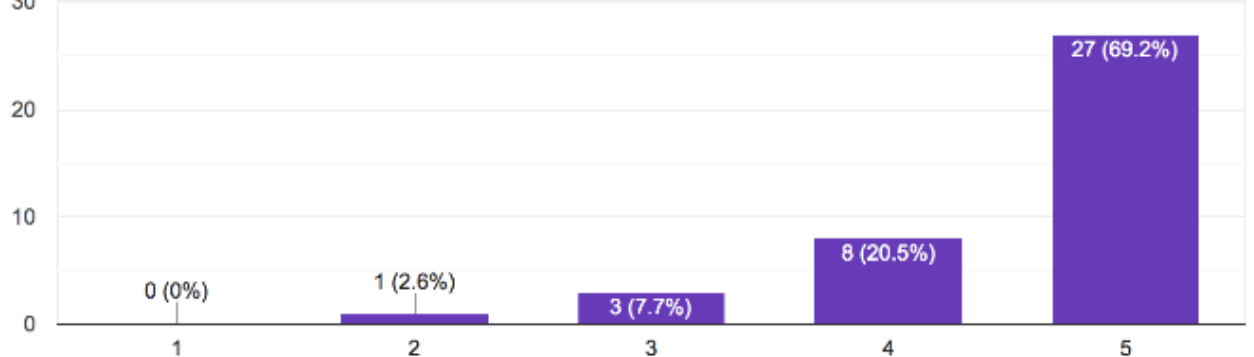



طرحت عدد من تساؤلات في استمارة الاستبيان حول المحور الثالث : الخيال الابداعي والصوت 9 - كان السؤال التاسع عن مدى اثارة الموسيقى المصاحبة لخيال المتلقي هل اثارت الموسيقى المصاحبه خيال المثلقى 39 responses

30

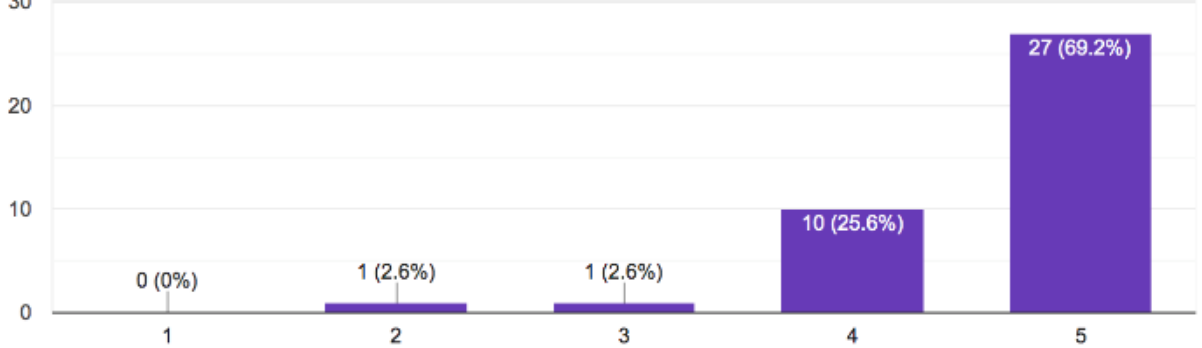

كان

السؤال العاثر عن مدى اثارة المؤثرات الصوتية الخاصة خيالك

هل اثارت المؤثرات الخاصة خيال المتلقي

39 responses

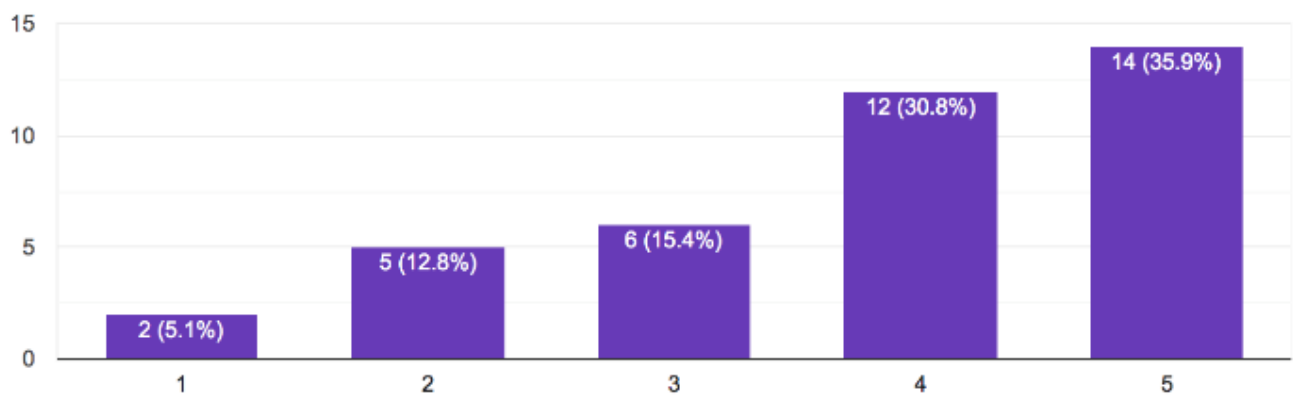

11 -كان السؤال الحادي عشر عن مدى اثارة الصمت لخبال المتلقي

هل اثاز الصمت خيال المتلقي

38 responses

30

20

10

0

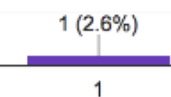

$0(0 \%)$ 
طرحت عدد من تساؤلات في استمارة الاستبيان حول المحور الرابع : الخيال الابداعي في الفيلم 12 -كان السؤال الثاني عشر هل تم فلك الثفر ات المتضمنة بالفيلم بسهولة

هل ثم فلك الشفر ات المتضمنه بالفيلم بسهولة

39 responses

30

20

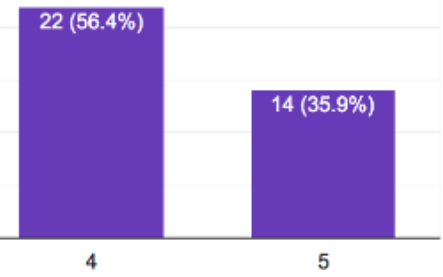

3 - كان السؤال الثالث عثر هل هذا الفيلم عمل ابداعي

هل هذا الفيلم عمل ابداعي

39 responses

40

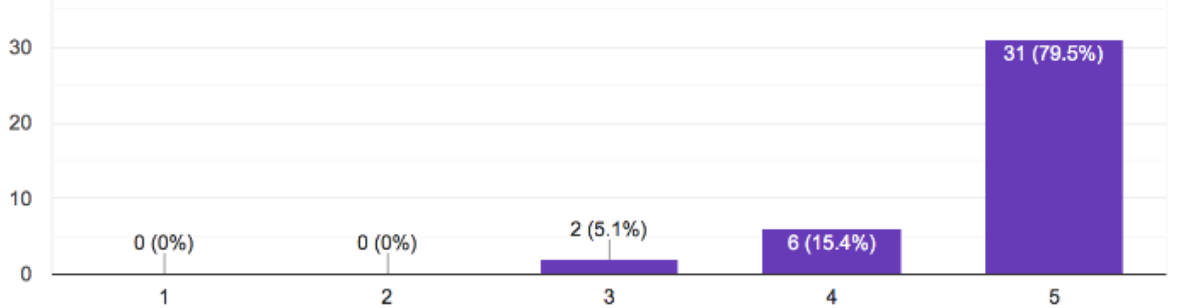

4 14 -كان السؤال الرابع عشر هل هذا الفيلم نسخ للواقع

هل هذا الفيلم نسخ للو اقع

39 responses

30

20

10

$6(15.4 \%)$

0

$\frac{0(0 \%)}{1}$

$\frac{0(0 \%)}{2}$

3 
15 -كان السؤال الخامس عشر هل ارتبط الابداع في الفيلم باثارة خيال المتلقي هل ارتبط الابداع في الفيلم باتخارة خيال المتلقي 39 responses

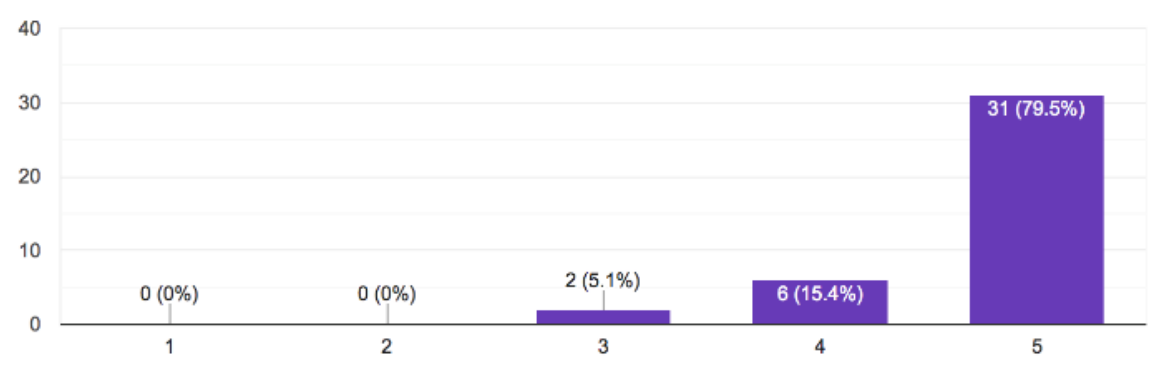

16 -كان السؤال السادس عشر هل يظهر مفهوم الابداع الخيالي في التصوير هل يظهر مفهوم الابداع الخيالي في التصوير

39 responses

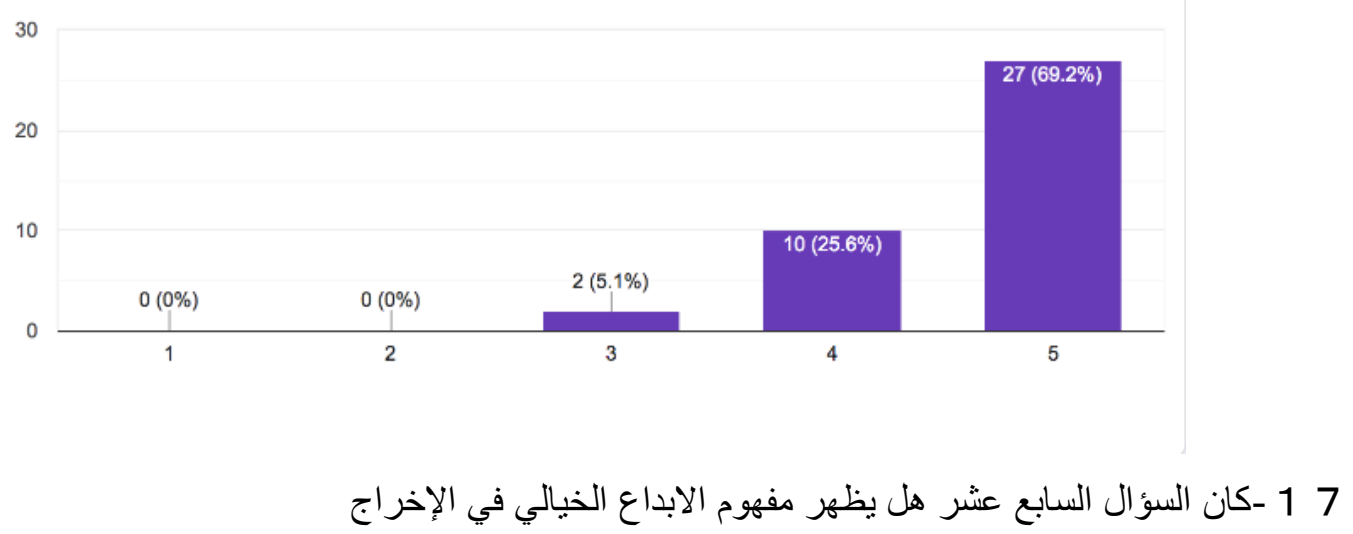

هل يظهر مفهوم الابداع الخيالي في الإخراج

39 responses

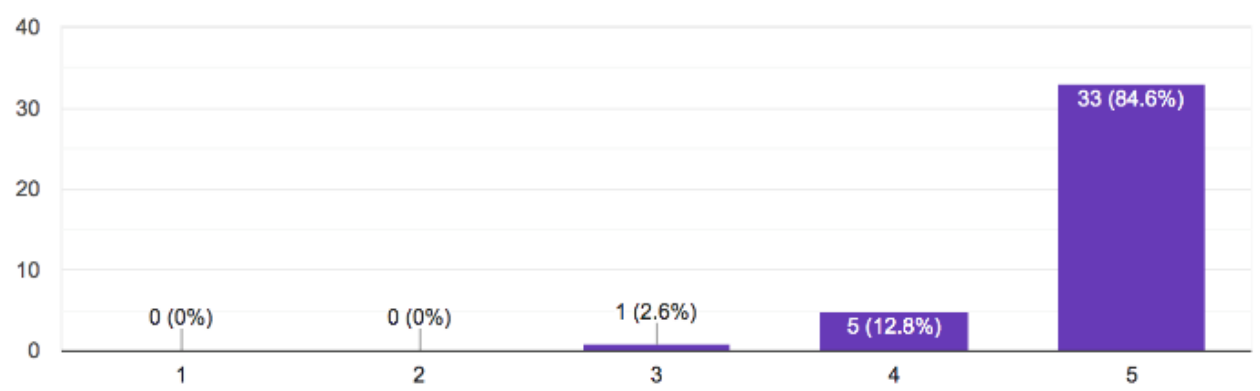


هل يظهر مفهوم الابداع الخيالي في الصوت

39 responses

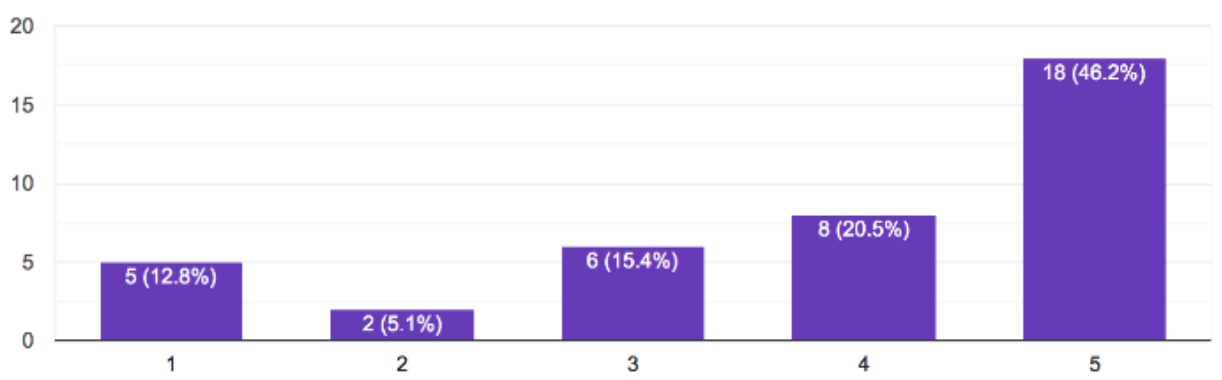

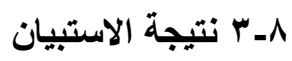

تحقق الخيال في فيلم عرق البلح على الرغم من انه لا ينتمي لفئة أفلام السينما الخيالية. واستقبل المشاهد هذه المعالجة

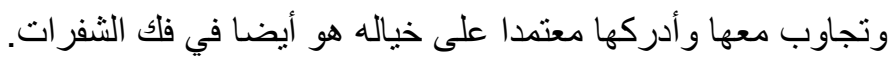

الاستنتاجات

يحتل الخيال الإبداعي جزءا كبيرا من نسيج الفيلم السينمائي البصري/السمعي وأيضا الدرامي. وتقدم السينما هذا الخيال الخالص في شكل بصري يبدو و اقعيا.

لا يرتبط الخيال فقط بالسينما الخيالية لكنه يظهر أيضا في كل أنواع الأفلام السينمائية من خلال عناصر الفيلم المختلفه وتطويعها المبدع خلال الفيلم. يظهر اتجاهان من الخيال السينما الاول لدى المبدع السينمائي في تطويع ادواته والثاني لاى الجمهور في فلك الثفرات وتفسير ها.

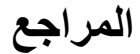

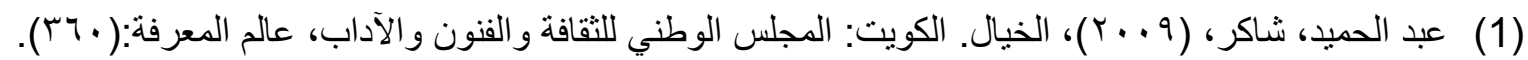
Abd El Hamed, Shaker. (2009), Al Khayal. Kuwait: National Council for Culture, Arts and Letters, Knowledge World: (360).

(2) لندا ـدافيدوف ، ( . . ب)، الذاكرة (الادر الك_الوعي) الدار الدولية للاستثمار ات الثقافية، ترجمة نجيب الفونس خزام، مصر، طبعة أولى. Linda., Davidov. (1 ${ }^{\text {st }}$ ed.). (2000). Memory (perception-awareness), targamah: Naguib Alfons Khuzam. Cairo: International House for Cultural Investments.

(3) Wollen ,Peter (1969), Signs and Meaning in the Cinema. London: Martin Secker \& Warburg Limited, 139.

(4) Scruton, Roger (1981), Photography and Representation. Chicago: The University of Chicago Press Journal, vol. (7), No.(3), 577-603. 
(5) Currie, Gregory (1995), Image and Mind: Film, Philosophy, and Cognitive Science. Cambridge: Cambridge University Press.

(6) Scruton, Roger (2009), Working Towards Art, British Journal of Aesthetics vol. 49, No. 4, 324.

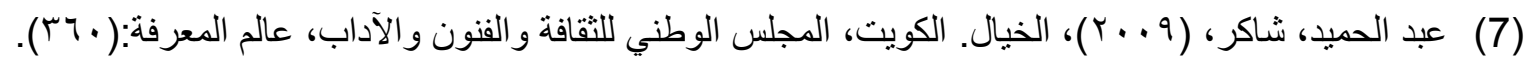
Abd El Hamed, Shaker. (2009), Al Khayal. Kuwait: National Council for Culture, Arts and Letters, Knowledge World: (360).

Abrams, Nathan (2001) lan Bell and Jan Udris, Studying Film. London: Arnold. (8)

(9) ستروك، جون (799 (19)، البنيوية وما بعدها: من ليفي شتراوس إلى دريدا، ترجمة محمد عصفور. الكويت: سلسلة

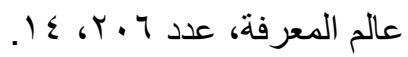

Struck, John (1996), Structuralism and Beyond: From Levi Strauss to Derrida, targamah: Muhammad Asfour. Kuwait: The World of Knowledge Series, No. 206, 14.

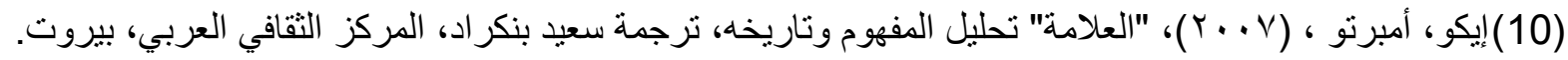
Eco , Umberto , (2008)"al3alamah"ta7aleel almafhoom wa tari5oh , (Saiid Binkrad, Trans), Bairoot,: almarkaz althakafi al3arabi.

Chandler, Daniel, (2002) The Basics, semiotics. London: Routledge press. 34.(11)

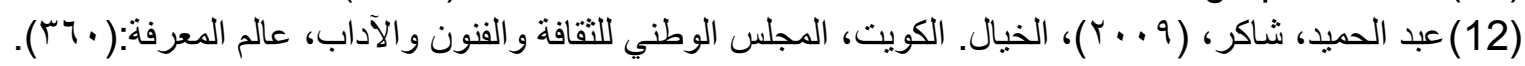
Abd El Hamed, Shaker. (2009), Al Khayal. Kuwait: National Council for Culture, Arts and Letters. Knowledge World: (360).

(13) Avarese, John, Landau, David (2017) Post Sound Design: The Art and Craft of Audio Post Production for Moving Image (the CineTech Guides to the Film Crafts), Bloomsbury Academic. 